\title{
Fentanyl-midazolam vs. midazolam-ketamine regarding patient sedation analgesia for emergency orthopedic procedures
}

\section{Ali Abdolrazaghnejad and Mohsen Banaie}

Department of Emergency Medicine, Sina Hospital, Tehran University of Medical Sciences, Tehran, Iran.

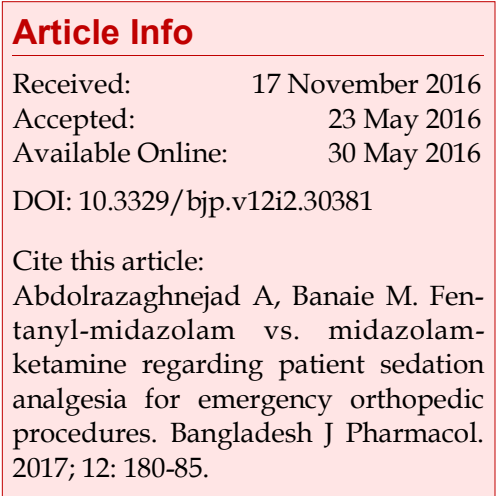

\begin{abstract}
The aim of the present study was to investigate two pharmaceutical groups including fentanyl-midazolam and midazolam-ketamine used as patient sedation analgesia for the orthopedic emergency procedures. This is a prospective randomized double-blind and placebo-controlled trial study. Trauma patients admitted to emergency department who needed emergency reduction were enrolled. Finally 81 patients with mean age of $31.7 \pm 20.6$ years old were participated $(64.2 \%$ male). It is likely that the combination of midazolamketamine had a better performance in terms of the duration of hypoxia $(\mathrm{p}=$ $0.01)$, and pain scores during reduction $(\mathrm{p}=0.001)$. However, adverse effects was higher in the midazolam-ketamine group compared to the fentanylmidazolam. The level of satisfaction of physicians and patients were the same.
\end{abstract}

\section{Introduction}

Orthopedic reductions are among the most prevalent procedures in the Emergency Department. These procedures are painful and stressful. Reduced anxiety and pain control are important issues that the emergency physicians are faced with (Migita et al., 2006). According to the American Emergency Physicians Association guideline 2005, Procedural Sedation and Analgesia (PSA) has been defined for the utilization of dissociative or sedative agents with or without analgesics during the painful procedures, provided that the performance of cardiorespiratory system is maintained (Baratloo et al., 2016; Bordo et al., 2008).

The potential benefits of effective sedation prior to reduction include the reduced anxiety and distress of the patient, providing comfort followed by more cooperation of patients, improvement of the success of the procedure and obviation the general anesthesia (Alimohammadi et al., 2014; Migita et al., 2006).

Although at present, many medications are accessible for PSA in the Emergency Departments. On the other hand, their adverse effects are still a considerable aspect in this regard. One of the recommendations to reduce the adverse effects of medications for PSA, is the use of drug combinations. According to available studies, the use of drug combinations, together with lowering the dose of drugs can compare with monotherapy and prevent the occurrence of adverse effects (Cevik et al., 2013).

According to the recent studies ketamine, midazolam and fentanyl which are the most commonly used drugs for PSA, will be useful if they are used for sedation of patients in appropriate doses under necessary supervision and monitoring (Cevik et al., 2013). The objective of the current study was to compare the effectiveness and side effects of two pharmaceutical groups of lowdose midazolam-ketamine and fentanyl-midazolam used for PSA during the reduction of dislocations and fractures in the Emergency Department.

\section{Materials and Methods}

\section{Study design}

This is a prospective double-blind randomized clinical 
trial conducted from March 2015 until June 2016 in the academic Emergency Department of Valiasr Hospital, Arak, Iran.

\section{Participants}

Traumatic patients admitted to the Emergency Department who were in need for emergency closed reduction due to fractures or dislocations were included. Patients with systolic blood pressure $<90 \mathrm{mmHg}$, pulse rate $<60$ beats/min, American Society of Anesthesiologists (ASA) Class I to II, chronic renal failure, liver failure and a known history of sensitivity to ketamine, midazolam or fentanyl were excluded.

\section{Intervention}

Patients were randomly assigned into midazolam-ketamine and fentanyl-midazolam groups using computerassisted randomization table. Drugs were prepared in two distinct syringes by the nurse and were administered for the patients by another nurse who was blind to the medications. Emergency physicians who were in charge of reduction, nurses administrating the medications and patients were blind to the type of treatment.

Dropping the $\mathrm{O}_{2}$ saturation below $90 \%$ or staying $\mathrm{SPO}_{2}$ under $95 \%$ for more than one min were considered as hypoxia and oxygen was administered via nasal cannula. Hypoxia, the need for oxygen or intubation, duration of hypoxia, time to onset of sedation, level of satisfaction of the emergency medicine specialist and the patient (five grades: Very poor, poor, moderate, good, and excellent), pain score during reduction by Visual Analogue Scale (VAS), $\mathrm{SPO}_{2}$, the success of the procedure, systolic blood pressure and pulse rate at 0,5 , $10,30,60,90$, and $120 \mathrm{~min}$ following the sedation implantation, the depth of sedation (on a 3-grade), any complications or side effects, duration of recovery, and hospital stay duration were recorded for all patients.

\section{Outcome}

Hypoxia, time to onset of sedation, duration of hypoxia, need for oxygen, and pain scores during reduction, recovery time and the depth of sedation were considered as primary outcome measured variables. Reduction success, patient and physicians' satisfaction, complications, and discharge time were set as secondary outcome measures.

\section{Statistical analysis}

The collected data were analyzed with statistical package for the social sciences (SPSS) software version 18.0 (SPSS Inc., USA). Data that showed normal distribution were presented as mean $\pm \mathrm{SD}$, and data that showed abnormal distribution were defined as median and interquartile range (IQR). Groups were compared with t-test; continuous variables with abnormal distribution were compared by MannWhitney U-test and categorical variables with abnormal distribution were compared using $\chi^{2}$-test. $\mathrm{P}$ values less than 0.05 were considered significant.

\section{Results}

\section{Demographic and baseline findings}

Of 488 patients admitted to the Emergency Department with limb injuries that required emergency closed reduction, 141 patients were evaluated for inclusion in the study, 60 of whom were excluded. Finally, 81 patients with were randomly assigned into each of the midazolam-ketamine group $(n=41)$ or fentanyl-midazolam group $(n=40)$. Figure 1 illustrates the study recruitment process. Demographic and baseline characteristics of participants are summarized in Table I. The mean age of the studied patients was $31.7 \pm 20.6$ years old $(64.2 \%$ male). The age $(p=0.52)$ and the sex distribution $(p=0.72)$, initial VAS of participants $(p=$ $0.6)$, and also frequency of fractures and dislocations ( $p$ $=0.32$ ) were not statistically different between the two groups.

\section{Primary outcomes}

Information on the primary outcome variables are shown in Table II. Hypoxia $(p=0.002)$ and its duration $(\mathrm{p}=0.01)$ in midazolam-ketamine group was significantly lower than fentanyl-midazolam group. All patients in both groups were in need for oxygen by mask or nasal cannula. Two patients in the fentanylmidazolam group was in the need of positive pressure ventilation. None of the patients in both groups did not need endotracheal intubations. Pain score during reduction in patients belonging to midazolam-ketamine group was significantly lower than in patients belonging to the fentanyl-midazolam group $(p=0.001)$. fentanyl-midazolam and midazolam-ketamine groups were similar in terms of the depth of sedation $(p=0.115)$ and recovery period $(p=0.9)$. Although, the time period from drug administration to onset of sedation was slightly shorter in midazolam-ketamine group butthe difference was not statistically significant $(p=0.08)$.

\section{Secondary outcomes}

Average hospital stay time of midazolam-ketamine group was significantly lower than fentanyl-midazolam group $(p=0.001)$. However, the frequency of drug side effects was significantly higher in midazolam-ketamine group $(p=0.001)$. In the midazolam-ketamine group, 5 patients had nausea and vomiting, 3 patients suffered from vertigo, 8 patients had recovery agitation, 2 patients developed fasciculation and 1 patient had hiccups; while the only side effects observed in the fentanyl-midazolam group were nausea, vomiting and dizziness. Success rate of procedure was observed in 40 participants $(97.6 \%)$ of the midazolam-ketamine group and 40 participants $(100 \%)$ of the fentanyl-midazolam 


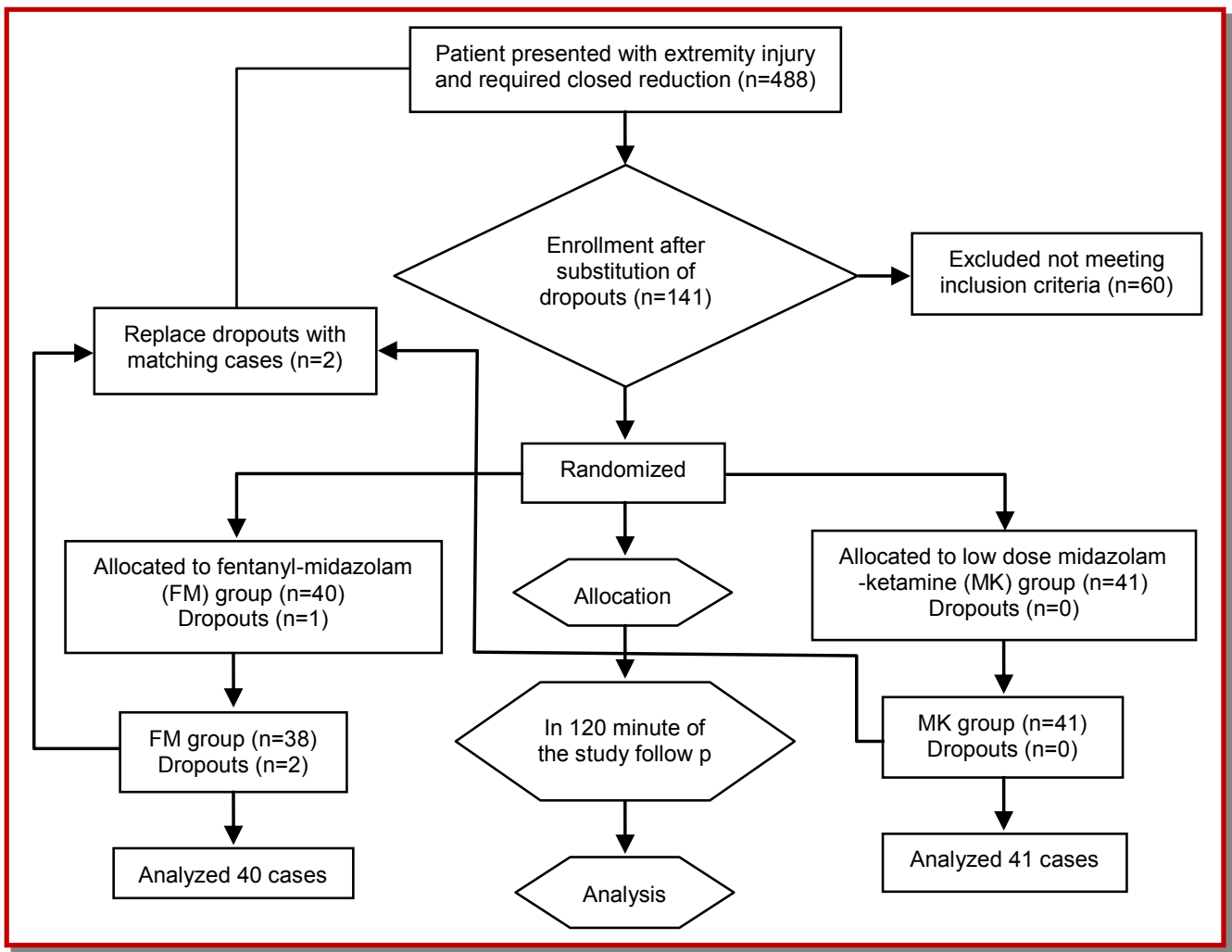

Figure 1: CONSORT flowchart of studied patients

\section{Table I}

\section{Demographic and baseline characteristics}

\begin{tabular}{|l|r|rc|}
\hline Variables & $\begin{array}{r}\text { Midazolam- } \\
\text { ketamine } \\
(\mathrm{n}=41)\end{array}$ & $\begin{array}{r}\text { Fentanyl- } \\
\text { midazolam } \\
(\mathrm{n}=40)\end{array}$ & $\mathrm{p}$ \\
\hline Age (year) & $32.1 \pm 21.3$ & $31.3 \pm 19.8$ & 0.52 \\
Sex & & & \\
Male & 28 & 24 & 0.72 \\
Female & 13 & 16 & \\
ASA class & & & \\
I & 34 & 33 & 0.69 \\
II & 7 & 7 & \\
Initial VAS & $8.4 \pm 3.1$ & $8.6 \pm 2.8$ & 0.60 \\
Last oral intake & $4.1 \pm 2.4$ & $4.2 \pm 1.9$ & 0.51 \\
(hour) & & & \\
Diagnosis & & & \\
Fractures & 26 & 19 & 0.32 \\
Dislocations & 15 & 21 & \\
\hline
\end{tabular}

group $(p=0.23)$. No significant difference was found between the level of satisfaction of physicians and patients in two groups (Table III). Systolic blood pressure was increased at 5, 10 and $30 \mathrm{~min}$ in the midazolam-ketamine group; while at the same times,
Table II

Outcomes of studied patients

\begin{tabular}{|c|c|c|c|}
\hline Variables & $\begin{array}{l}\text { Midazolam } \\
\text {-ketamine } \\
(n=41)\end{array}$ & $\begin{array}{l}\text { Fentanyl- } \\
\text { midazolam } \\
\quad(n=40)\end{array}$ & $\mathrm{p}$ \\
\hline Hypoxic event & 19 & 29 & 0.002 \\
\hline Oxygen required & 20 & 30 & 0.07 \\
\hline $\begin{array}{l}\text { Duration of hypoxia } \\
\text { (Sec) }\end{array}$ & $52.2 \pm 11.3$ & $94.3 \pm 22.1$ & 0.010 \\
\hline \multicolumn{4}{|l|}{ Depth of sedation } \\
\hline Mild & 0 & 0 & 0.115 \\
\hline Moderate & 8 & 11 & \\
\hline Deep & 33 & 29 & \\
\hline Onset of sedation (min) & $1 \pm 0.34$ & $2 \pm 1.1$ & 0.080 \\
\hline VAS during procedure & $1.4 \pm 0.1$ & $3.1 \pm 1.1$ & 0.001 \\
\hline Recovery period (min) & $30 \pm 32.7$ & $31.5 \pm 36.1$ & 0.900 \\
\hline Adverse effects & & & 0.001 \\
\hline $\begin{array}{l}\text { Nausea and vomit- } \\
\text { ing }\end{array}$ & 5 & 2 & 0.001 \\
\hline Vertigo & 3 & 2 & 0.001 \\
\hline Recovery agitation & 8 & 0 & 0.001 \\
\hline Fasciculation & 2 & 0 & 0.001 \\
\hline Hiccup & 1 & 0 & 0.001 \\
\hline Successful procedure & 40 & 40 & 0.230 \\
\hline Discharge time (hour) & $2.1 \pm 0.51$ & $2.9 \pm 1.1$ & 0.001 \\
\hline
\end{tabular}


Table III

\begin{tabular}{|c|c|c|c|}
\hline Satisfaction & $\begin{array}{l}\text { Midazolam- } \\
\text { Ketamine } \\
(n=41)\end{array}$ & $\begin{array}{l}\text { Fentanyl- } \\
\text { Midazolam } \\
(\mathrm{n}=40)\end{array}$ & $\mathrm{p}$ \\
\hline \multicolumn{4}{|l|}{ Physicians } \\
\hline Excellent & 29 & 23 & \multirow[t]{5}{*}{0.9} \\
\hline Good & 5 & 11 & \\
\hline Moderate & 4 & 4 & \\
\hline Poor & 3 & 2 & \\
\hline Very poor & 0 & 0 & \\
\hline \multicolumn{4}{|l|}{ Patients } \\
\hline Excellent & 28 & 24 & \multirow[t]{5}{*}{0.14} \\
\hline Good & 6 & 10 & \\
\hline Moderate & 5 & 5 & \\
\hline Poor & 2 & 1 & \\
\hline Very poor & 0 & 0 & \\
\hline
\end{tabular}

systolic blood pressure was reduced in the fentanylmidazolam group.

\section{Discussion}

According to the present study findings, it is likely that the midazolam-ketamine group had a better performance in terms of the onset of sedation, pain score during reduction, and duration of hypoxia. However, the adverse effects were higher in the midazolamketamine groups compared to the fentanyl-midazolam group. Level of satisfaction of physicians and patients in two groups were the same.

In a randomized controlled study on 260 pediatric patients regarding orthopedic procedures, it was found that ketamine-midazolam combination is safer and more effective than fentanyl-midazolam (Kennedy et al., 1998). In a double-blind randomized trial similar to our study, researchers examined the effect of midazolam-fentanyl and midazolam-ketamine combinations on 61 orthopedic emergency patients' sedation (Cevik et al., 2013). It seems that both combinations are useful for sedation of patients. However, due to less risk of hypoxia, and less pain score during reduction in midazolam-ketamine group, this drug combination is more appropriate for sedation in orthopedic emergency patients. Results of the study conducted by Cevik et al are similar to the present study not only in terms of the risk of hypoxia and pain score, but also in terms of the more adverse effects of midazolam-ketamine group compared to the midazolam-fentanyl group.

Based on previous studies, the incidence of hypoxia in the midazolam-ketamine and fentanyl-midazolam groups are in the range of 6-7 and $10-20 \%$ respectively (Hostetler et al., 2002; Kennedy et al., 1998; Roback et al., 2005). In the present study, hypoxia was observed in $46.3 \%$ of participants in midazolam-ketamine group and $72.5 \%$ of the participants in fentanyl-midazolam group. None of the patients have had the experience of serious event, and no one was intubated; but two patients in fentanyl-midazolam group required intermittent positive pressure ventilation using valve-maskballoon. Although the lack of oxygen, as determined by previous studies, was more common for fentanylmidazolam group. Our findings for hypoxia were considerably higher than what was already reported (Cevik et al., 2013; Godwin et al., 2005; Hostetler et al., 2002; Kennedy et al., 1998; Roback et al., 2005). The genetic characteristics of participants, using standard drug dose without titration, and also considering a lower threshold for defining hypoxia $\left(\mathrm{SPO}_{2}<90 \%\right)$ were impressive. Titration of medication doses and the use of supplemental oxygen may help reduce the incidence of hypoxia.

Kennedy et al compared the combination of midazolam-ketamine vs fentanyl-midazolam for pediatric patients and reported higher scores of anxiety and pain, higher family anxiety, and lower satisfaction of orthopedic surgeon for fentanyl-midazolam (Kennedy et al.,1998). Godambe et al reported no difference regarding VAS score and emergency physician and nurse satisfaction between the combination of midazolam-ketamine vs propofol-fentanyl. However, it was reported that observational scale of behavioural distress score was lower in the ketamine group (Godambe et al., 2003). Jamal et al found no significant difference between and procedure success rate and the pain scores during reduction between the groups of fentanyl-midazolam and ketamine (Jamal et al., 2011).

In current study, the average pain score during reduction was lower in the midazolam-ketamine group (MK: $1.4 \pm 0.1$ vs FM: $3.1 \pm 1.1$ ) which is consistent with the results of previous studies, including the study conducted by Cevik (Cevik et al., 2013). According to the results of present study, the success rate of the procedures in both groups was roughly equal. Comparative studies among children show high satisfaction of physician and patient/family in the ketamine group; however, no difference was found in this regard between the two groups in the present study.

Many high-risk side effects occur in the first $25 \mathrm{~min}$ after drug administration and the mean time between 25 min. Newman et al observed side effects in $13 \%$ of patients, $64 \%$ of which were seen in the Emergency Departments (Bailey et al., 1990; Newman et al., 2003). Therefore, the follow-up time used in the present study could be considered enough to see the most side effects. 
Based on previous evidence, the usual side effects such as nausea and vomiting was reported in a range between 3.6 and $29 \%$ for the midazolam-ketamine group, and in the range of 1.8 to $7 \%$ for the fentanylmidazolam group (Roback et al., 2005; Sener et al., 2011; Wathen et al., 2000). In current research, nausea and vomiting was observed in $12.1 \%$ of participants in the midazolam-ketamine group and $5 \%$ of the participants in the fentanyl-midazolam group, which is less than those reported in previous studies.

Recovery agitation is associated with the use of ketamine, which is, based on reports, in the range of 5.7 $-7 \%$ in midazolam-ketamine mixture. In the present study, the incidence of recovery agitation was $19 \%$ which was higher compared to the rates reported by Sener et al (Sener et al., 2011).

According to the present study, no difference was seen between the groups in terms of recovery period and sedation depth. The higher incidence of recovery agitation may be explained with the use of higher doses of ketamine and lower doses of midazolam in midazolam-ketamine combination used in this study.

The ASA recommends to avoid the oral intake of clear liquid at least 2 hours and solid food at least 6 hours prior PSA, respectively (Committee, 2011; Miller et al., 2005). A prospective observational study showed no differences in the incidence of vomiting, airway complications, and other negative effects during PSA in fasting and non-fasting groups (Agrawal et al., 2003). In their report, Godwin et al said that recent food consumption is not a contraindication for PSA (Godwin et al., 2005).

According to the data, in general anesthesia, the risk of aspiration is $1: 3420$ and the risk of death is $1: 125109$. According to reports, many of aspirations occur during intubation or extubation (Green et al., 2002; Miller et al., 2005). In the present study, no patient required advanced airway management or even airway maneuver. Although in the present study, the recommendations of ASA was not strictly followed, and even patients with recent intake were enrolled; however, aspiration did not occur in any of participants. In the present study, as expected, SBP levels increased in the midazolam-ketamine group and decreased in the fentanyl-midazolam group. This finding was consistent with the results of the study conducted by Cevik E (Cevik et al., 2013).

Although it is advised to determine the exact dose of opiates and sedatives, the weight-adjusted dose was used in this study, and individual differences were neglected for standardization. In addition, certain factors such as patients with fractures or dislocations and the need to monitor such patients in a separate unit of the Emergency Department reduced significantly the number of patients included. Considering the low number of participants, some variables did not follow a normal distribution and non-parametric tests were used perforce. Patients were just followed in the Emergency Department and late outcomes was not followed.

\section{Conclusion}

It is likely that the combination of midazolam-ketamine had a better performance in terms of the onset of sedation, the duration of hypoxia, and pain scores during reduction than fentanyl-midazolam.

\section{Ethical Issue}

Protocol of the study was approved by ethics committee of Arak University of Medical Sciences. The investigators were committed to Helsinki Declaration Principles. Written consent was obtained from all of patients.

\section{Conflict of Interest}

All authors have completed the ICMJE uniform disclosure form and declare no support from any organization for the submitted work.

\section{Acknowledgement}

The research team wishes to thank vice chancellor of research of Arak University of Medical Sciences for the financial support and also patients who contributed to this research.

\section{References}

Agrawal D, Manzi SF, Gupta R, Krauss B. Preprocedural fasting state and adverse events in children undergoing procedural sedation and analgesia in a Pediatric Emergency Department. Ann Emerg Med. 2003; 42: 636-46.

Alimohammadi H, Baratloo A, Abdalvand A, Rouhipour A, Safari S. Effects of pain relief on arterial blood $\mathrm{O} 2$ saturation. Trauma Mon. 2014; 19: e14034.

Bailey PL, Pace NL, Ashburn MA, Moll J, East KA, Stanley TH. Frequent hypoxemia and apnea after sedation with midazolam and fentanyl. Anesthesiology 1990; 73: 826-30.

Baratloo A, Rouhipour A, Forouzanfar MM, Safari S, Amiri M, Negida A. The role of caffeine in pain management: A brief literature review. Anesth Pain Med. 2016; 6: e33193.

Bordo D, Chan S, Shin P. Patient satisfaction and return to daily activities using etomidate procedural sedation for orthopedic injuries. West J Emerg Med. 2008; 9: 86-90.

Cevik E, Bilgic S, Kilic E, Cinar O, Hasman H, Acar AY, Eroglu M. Comparison of ketamine-low-dose midozolam with midazolam-fentanyl for orthopedic emergencies: A doubleblind randomized trial. Am J Emerg Med. 2013; 31: 108-13.

Committee ASoA. Practice guidelines for preoperative fasting 
and the use of pharmacologic agents to reduce the risk of pulmonary aspiration: Application to healthy patients undergoing elective procedures: An updated report by the American Society of Anesthesiologists Committee on Standards and Practice Parameters. Anesthesiology 2011; 114: 495.

Godambe SA, Elliot V, Matheny D, Pershad J. Comparison of propofol/fentanyl versus ketamine/midazolam for brief orthopedic procedural sedation in a Pediatric Emergency Department. Pediatrics 2003; 112: 116-23.

Godwin SA, Caro DA, Wolf SJ, Jagoda AS, Charles R, Marett BE, Moore J. Clinical policy: Procedural sedation and analgesia in the Emergency Department. Ann Emerg Med. 2005; 45: 177-96.

Green SM, Krauss B. Pulmonary aspiration risk during Emergency Department Procedural Sedation: An examination of the role of fasting and sedation depth. Acad Emerg Med. 2002; 9: 35-42.

Hostetler MA, Barnard JA. Removal of esophageal foreign bodies in the pediatric ED: Is ketamine an option? Am J Emerg Med. 2002; 20: 96-98.

Jamal S, Fathil S, Nidzwani M, Ismail A, Yatim F. Intravenous ketamine is as effective as midazolam/fentanyl for procedural sedation and analgesia in the Emergency Department. Med J Malaysia. 2011; 66: 231-33.

Kennedy RM, Porter FL, Miller JP, Jaffe DM. Comparison of fentanyl/midazolam with ketamine/midazolam for pediatric orthopedic emergencies. Pediatrics 1998; 102: 95663.

Migita RT, Klein EJ, Garrison MM. Sedation and analgesia for pediatric fracture reduction in the Emergency Department: A systematic review. Arch Pediatr Adolesc Med. 2006; 160: 46-51.

Miller MA, Levy P, Patel MM. Procedural sedation and analgesia in the Emergency Department: What are the risks? Emerg Med Clin North Am. 2005; 23: 551-72.

Newman DH, Azer MM, Pitetti RD, Singh S. When is a patient safe for discharge after procedural sedation? The timing of adverse effect events in 1,367 pediatric procedural sedations. Ann Emerg Med. 2003; 42: 627-35.

Roback MG, Wathen JE, Bajaj L, Bothner JP. Adverse events associated with procedural sedation and analgesia in a Pediatric Emergency Department: A comparison of common parenteral drugs. Acad Emerg Med. 2005; 12: 508-13.

Sener S, Eken C, Schultz CH, Serinken M, Ozsarac M. Ketamine with and without midazolam for Emergency Department Sedation in adults: A randomized controlled trial. Ann Emerg Med. 2011; 57: 109-14.

Wathen JE, Roback MG, Mackenzie T, Bothner JP. Does midazolam alter the clinical effects of intravenous ketamine sedation in children? A double-blind, randomized, controlled, Emergency Department trial. Ann Emerg Med. 2000; 36: 579-88. 


\section{Your feedback about this paper}

1. Number of times you have read this paper 0

2. Quality of paper Click

3. Your comments

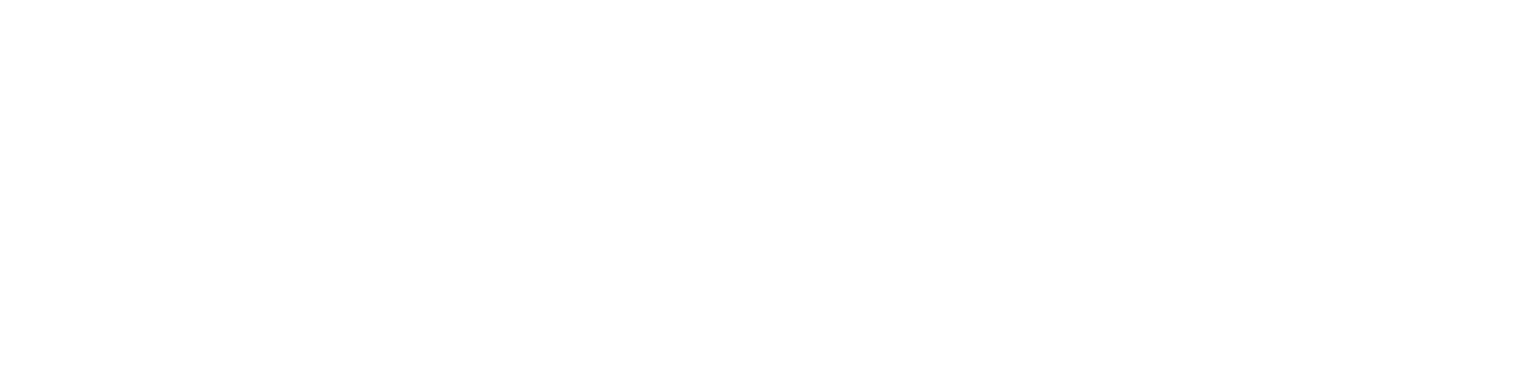

